\title{
Assessing students' errors in mathematical translation: From symbolic to verbal and graphic representations
}

\author{
Nurrahmawati $^{1}$, Cholis Sa'dijah $^{2}$, Sudirman $^{3}$, Makbul Muksar $^{4}$ \\ ${ }^{1,2,3,4}$ Mathematics Education Study Program, Universitas Negeri Malang, Indonesia \\ ${ }^{1}$ Mathematics Education Study Program, Universitas Pasir Pengaraian, Indonesia
}

\begin{tabular}{l} 
Article Info \\
\hline Article history: \\
Received Jun 29, 2020 \\
Revised Dec 10, 2020 \\
Accepted Jan 27, 2021 \\
\hline Keywords: \\
Graphical representations \\
Multiple representations \\
Symbolic representations \\
Translation between \\
representations \\
Verbal representations
\end{tabular}

Article Info

Article history:

Received Jun 29, 2020

Revised Dec 10, 2020

Accepted Jan 27, 2021

\section{Keywords:}

Graphical representations Multiple representations Symbolic representations representations Verbal representations

\begin{abstract}
Translation skills are very important possessed by students, but currently, there are still many students who have difficulty in translating between representations. The purpose of this study is to analyze students' errors in translating from symbolic representations to verbal and graphic representations. This research was descriptive study with qualitative approach. Tests are given to junior high school students. From the results of data analysis, it is obtained that in translating from symbolic to verbal forms (problems in daily life) that are following the given system of equations, students are still unable to make representations correctly. When students are asked to translate into graphical form, students are still unable to draw complete graphs and errors made by students are misinterpretation and implementation errors, so they cannot maintain the semantic congruence between source representation and target representation. Based on this, it is necessary to make a learning plan that can improve students' ability to translate between representations.
\end{abstract}

This is an open access article under the CC BY-SA license.

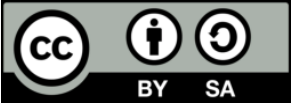

\section{Corresponding Author:}

Sudirman

Mathematics Education Study Program

Universitas Negeri Malang

J1. Semarang No 5, Malang, 65145, Indonesia

Email: sudirman.fmipa@um.ac.id

\section{INTRODUCTION}

Representation plays a pivotal role in the learning and research activities of mathematics education [1-8]. According to National Council of Teacher of Mathematics (NCTM) [2], there are three representational goals for school mathematics, namely: 1) creating and using representations to organize, record, and communicate mathematical ideas; 2) choosing, applying, and translating between mathematical representations to solve problems; and 3) using representations to model and interpret physical, social, and mathematical phenomena. Based on these three objectives, the ability of representation is very important possessed by students.

Not only have representation capabilities, but students are also expected to have multiple representation capabilities [2, 4, 7, 9-19]. Ainsworth [20] states that in a process of problem formulation, students must have multiple representation skills to articulate the same problem in various forms or views. Blake and Scanlon [10] and Hwang, et al. [11] stated that students' multiple representation skills are the key to successful mathematical problem-solving. Based on this, the ability of multiple representations is also very important for students to have, for example in the problem-solving process. In terms of solving problems, sometimes students have to translate other forms of problems to facilitate the problem-solving process. So, translating between representations is very important in mathematics learning activities. 
Some experts agree that the ability to translate between representations is very important for students $[2,6,15,17,18,20-33]$. This is because this ability is one of the factors that influence mathematics learning and success in solving problems [17, 27, 33, 34]. In general, the term translational and translational processes refer to psychological, intellectual, or cognitive processes that are classified in transforming information encoded in one mathematical representation (source) to another (target) [34]. Regarding the translation process, many researchers agree that the purpose of translation is to maintain semantic congruence, namely the mathematical meaning between source representation and target representation [35]. Teachers need to know how students' abilities translate between representations. However, sometimes teachers do not realize the importance of using various representations in their learning $[4,36]$, and do not pay attention to the forms of representation developed by students, whether students are able or not to make representations other than the concepts learned. The teacher should know in which process students have difficulty in the translation process and where the error lies. Lesh, et al. [13] found that translation disability was a significant factor in influencing mathematics learning and problem-solving performance. To diagnose student learning difficulties or to identify what will be done for the next learning, the teacher can provide questions by presenting ideas in one representation mode and asking students to make illustrations, descriptions, or present the same ideas in other modes.

Several studies relating to student representations and abilities in translating between representations [5-7, 12, 21, 30, 32, 37-48] for example, the research results of Zhe [5] found that many students had obstacles in understanding and translating mathematical language. For example, they cannot truly understand mathematical language, cannot understand the relationship between mathematical languages, and cannot translate graphic language into verbal language, or verbal language into symbolic language. These obstacles directly affect the mathematical representation of students. $\mathrm{Ng}$ and Lee [45] state that students face obstacles in representing word problem (verbal representation) into formal symbolic algebraic forms.

The results of the Sert [49] analysis indicate that students feel difficulties in verbal representation. Furthermore, one of the results of research by Bossé, et al. [50] stated that generally students can translate from symbolic to graphical forms, and students are rarely able to translate from symbolic to verbal forms. Ozyildirim, et al. [25] research results show that students have great difficulties in the process of translational representation, both in translating from tabular to algebraic forms, verbal algebra and verbal algebra, and diagrams to algebra. Gürbüz and Şahin [46] stated that the most difficult translation for students is to translate verbal representations, tables, equations into graphs. Furthermore, the results of research by Hattikudur, et al. [43] show that students find it difficult to construct images because they have misconceptions about graphics, such as height and slope, reading and compiling graphs of points (each separately). This deficiency may arise with a lack of knowledge about the concept of one representation to another representation, or confusion between the process of graphics and graphics as a product. Johar and Lubis [48] revealed that the error in representation generally occurs due to the students are not familiar with the problem requiring representation to solve it.

Adu-Gyamfi, et al. [21] investigated students' translational tasks between numerical, symbolic, and graphical mathematical representations and found three common types of errors that emerged and calculated the frequency of each type of error. Common errors that arise are implementation error, interpretation error, and preservation error. Another result of the research by Bossé, et al. [38] related to analyzing the activities of students in the process of translating algebraic linguistics, determining the types of mistakes made, and recognizing the frequency of errors that occur. Bossé, et al. [23] conducted research focusing on the process of translating students from graphs to symbols based on students' mathematical ability levels. Furthermore, Duru and Koklu [41] also researched the translation between modes of text representation and algebra. The results of his research revealed that students find difficulty in translating from text mode into algebraic equations using symbols, besides, students also find difficulties to translate from symbolic modes into the text because of weaknesses in reading comprehension. Clement [39] research results stated that students in tertiary institutions have difficulty in making the form of equality of the given word problem.

Baker, et al. [37] research results focus on testing student performance on "interpreting, generating, and selecting" external representations for data analysis. According to the results of the study, the overall performance of students in the interpretation of graphics is moderate, but in the selection and manufacture of graphics, student performance is not good. Gagatsis and Shiakalli [24], in their research, asked students to make graphical sketches and write algebraic expressions that correspond to the verbal representations presented. Furthermore, asking students to write verbal and algebraic representations that correspond to the graphical representations given. According to the results of his research, it is evident that every time a graphical representation is involved in a translation task, the percentage of success is lower.

Based on these results, it appears that many students have difficulty translating between representations and the study focuses on which translations are most problematic for students. Meanwhile, research relating to what forms of errors made by students has not been much studied in-depth, especially in 
translating from symbolic forms to forms of verbal and graphic representations. In this study student performance against the translations that have been produced is assessed. Furthermore, in previous studies, it was also seen that most of these studies examined how students translate from verbal to symbolic forms, whereas research on students' errors in translating from symbolic to verbal and graphic forms has not been studied. Even though the ability of students to make graphical representations is very important in learning mathematics and solving problems $[43,51,52]$ as well as the ability of students to make verbal situations in the context of everyday life is also important [50].

In the context of this study, there are unanswered questions about the quality of making and translating between representations, and the questions of this study are worth answering. Not many studies have been reported that discuss the quality of representations that have been made by students, especially in Indonesia. The purpose of this study is to determine the difficulties and analyze forms of student errors in translating from symbolic representations to verbal and graphic representations as well as what factors influence the students' ability to translate between representations.

The results of this study are important for the review of learning in the classroom that is what the teacher must do so that students can translate between representations. On the other hand, the findings of this study are considered to contribute in developing a learning approach that can improve students' abilities in translating between representations.

\section{RESEARCH METHOD}

This research is a descriptive study with a qualitative approach. The test was given to 73 grade 8 students from two junior high schools in Rokan Hulu Regency, Riau, Indonesia. In this study, the ability to translate between representations is a matter in the form of symbolic representations and then students are asked to translate them into other forms of representation, namely the graphics and verbal. The questions presented are related to the material of the two-variable linear equation system (TVLES), where this material is material that students have learned before. The questions given are presented in Figure 1.

$$
\begin{aligned}
& \text { Given the equation system as follows: } \\
& \begin{array}{c}
2 a+3 b=18 \\
a+b=8
\end{array} \\
& \text { b. Look for the solution of the equation system above! } \\
& \text { c. Make a word problem in everyday life that fits the problem of the equation system } \\
& \text { above! } \\
& \text { d. Draw a graph from the system of equations above, if } a, b \text { is a real number! }
\end{aligned}
$$

Figure 1. Research instruments

In the first problem, students are asked to determine the completion of the given equation system. Next, students are asked to solve the second problem, which is making a verbal representation of the system of equations given to the first problem. The verbal representation referred to in this study is to make the problem situation related to daily life following the problem of the equation system presented. In the third problem, students are asked to present the given equation system in the form of graphical representation. The focus of this research is on questions (b) and (c), namely how students translate from symbolic to verbal representation and how students translate from symbolic to graphic representation.

The test is given to find out how students' mathematical translation skills and what are the forms of student error in doing the translation. In the translational questions presented in this study, the source representations are symbolic representations while the target representations are verbal and graphical. After the test, several students are interviewed to find out more about the answers that have been written and whether students have ever solved questions like the questions presented in this research.

Data analysis in this study uses descriptive analysis and content analysis methods. The steps in the analysis of this research data are: 1) All students 'answers are identified and classified based on the characteristics of students' answers; 2) Based on these classifications, the next is the students' answer errors in translating between representations in the analysis, 3) Several students interviewed related to the answers that have been written; 4) Make conclusions based on the students' errors in translating from symbolic to verbal and graphic forms. 
In analyzing the symbolic representation to verbal representation, the answers generated by students are seen whether students can make a problem situation that is by the system of equations presented in the problem, whether students can maintain semantic congruence between source and target representations or not. If not, then what forms of student error will be analyzed here. While the analysis of student errors in translating from symbolic representations to graphical representations, the definition of error used is the definition according to Adu-Gyamfi, et al. [21]. The first error is an implementation error, which is the type of error that usually occurs when a step in an algorithm is run incorrectly. The general description of this behavior is that "students make computational errors." The second error is interpretation error, ie students misjudge, characterize, or rule out the attributes or properties of the source or target representation. The general description of misinterpretation is "students do not understand how applying or interpreting the traits" that define the source and/or target representation. This can occur at any time during the translation process and sometimes involves "transitional representations." Transitional representations are intermediary representations that are created when a student is more comfortable moving to target representations through several other representations that are different from the source. The third type of error is preservation error. Here students correctly maintain the semantic congruence between source and target representations for attributes or attributes that are self-recognized, but fail to ensure that the attribute or other relevant traits are also translated correctly. This usually happens when the key attribute of the source representation is unknown, but the key is not properly encoded in the target representation. The general description of this situation is that "the student did not verify that all key attributes of the source and target representations were correctly coded."

\section{RESULTS AND DISCUSSION}

The results of student answers related to the first problem, namely students are asked to determine the completion of the TVLES given. The results of student answers indicate that students can determine the completion of the TVLES given, ie the completion obtained is $(6,2)$.

\subsection{Students' errors in translating from symbolic to verbal representations}

In the second problem, students are asked to translate the given equation system into a verbal representation. Students are asked to create problem-related situations in everyday life. Based on the answers that have been written by students, there are some errors made by students. The first error is a problem situation or a word problem written by students is not logical. Examples of student response errors are shown in Figure 2.

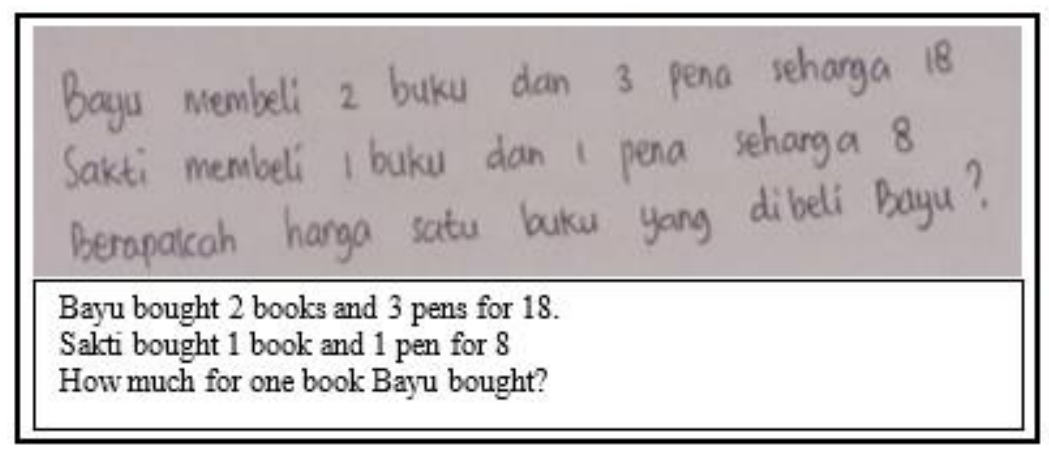

Figure 2. Examples of illogical answers of students to the word problem (S32)

Based on Figure 2, it can be seen that in making a problem situation or a word problem in daily life, students relate it to the price of an item, namely the purchase of books and pens. For the purchase of 2 books and 3 pens purchased for 18 and the purchase of 1 book and 1 pen purchased for 8 . Students can indeed do the translation by the given equation system, but the problem situation presented by students is not logical. If it is related to students' daily lives, namely in Indonesia, there is no price of books and pens that can be purchased at prices as written, so the answers written by these students are not logical. So in making a problem situation in daily life, students must not only pay attention to the given equation, but students must also pay attention to the context of the problem created, whether logical or not. 
The results of the interview showed that when students were asked to read and re-understand the situation of the problem they had written, the student realized that what he had written was not logical. When asked to create a situation from problems other than problems related to determining the price of goods, the student does not yet have an idea to create another problem situation. Based on this it is seen that students feel it is difficult to make a problem situation other than problems related to determining the price of goods. The second error in making real word problems related to daily life is the mismatch between the written problem and the equation given. The error can be seen in Figure 3.

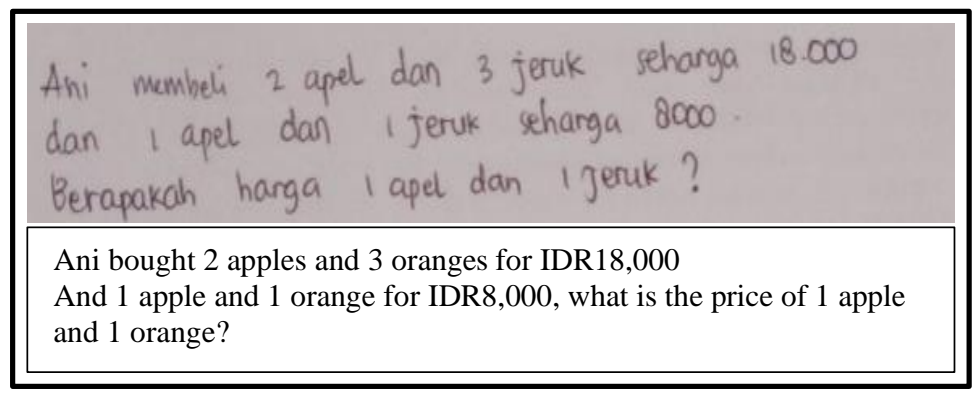

Figure 3. Examples of student responses in creating problem situations in daily life (S46)

Based on Figure 3, it can be seen that in making word problems, students also make questions about the price of an item. The answers that have been written by students can be said to be logical and complete, but not following the problem of the given equation system. When students are asked to create a problem situation other than the price of an item, students also do not yet have an idea to create a problem situation. The third error that students make in creating problem situations is that the word problem written by students has nothing to do with the equation system given. Examples of student response errors are shown in Figure 4.

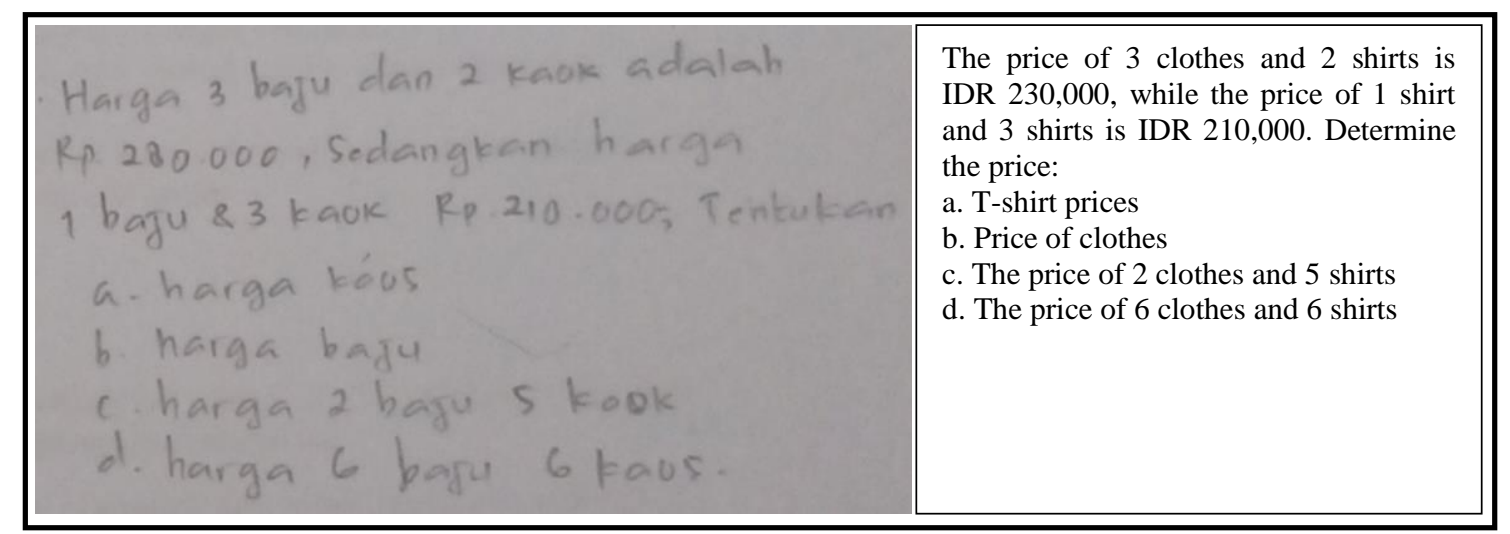

Figure 4. Other examples of students' answers in creating problem situations in daily life

Figure 4 shows that the problem situation generated by students has nothing to do with the equation system presented in the problem. This means that students are also not able to present verbal representations appropriately. The result of the interview shows that the students suddenly realize that the word problem must be in line with the equation system presented in the task. It is mentioned when they are asked to convey what is known and asked about the problem. This shows that students do not read in detail the instructions of the questions given. When students are requested to make other word problems, they are still not able to make representations correctly. In addition, the fourth error that students make when translating into verbal representation is shown in Figure 5. 


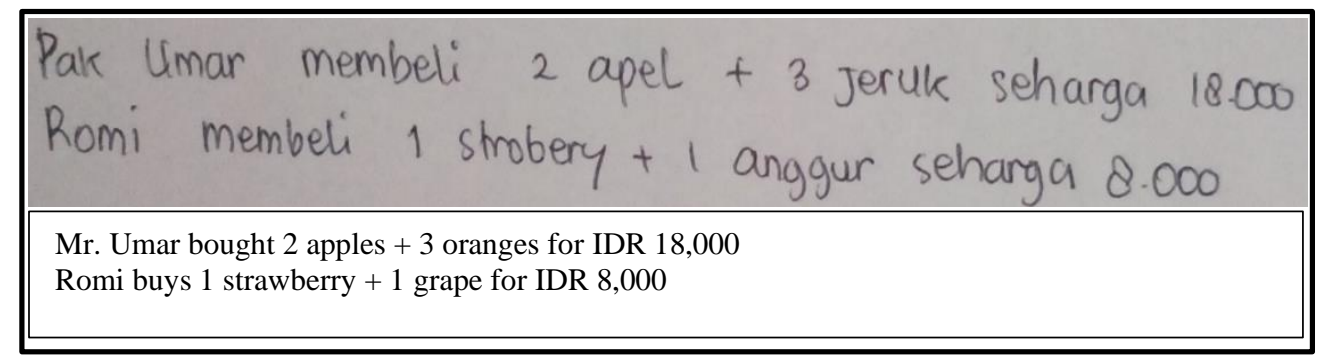

Figure 5. Another example of students' errors in creating problem situations in daily life (S21)

In Figure 5, it can be seen that the questions written by students do not represent a problem situation that is by the concept of a two-variable linear equation system. In fact, the same symbol carries the same meaning, the students interpreted differently. This causes an error in the meaning of the symbol. The results of the student's answers show that students do not understand the TVLES concept so that students have difficulty in writing problems in everyday life. The results of the interviews showed that students did not understand the concept of the two-variable linear equation system well.

Based on the answers presented in Figure 2 to Figure 5, it was seen that each student had a different answer in making a word problem following the given equation system. However, interestingly, all students create problem situations related to determining the price of an item. Some students make a problem situation in everyday life illogically, and some students make a problem situation in everyday life logically but not yet by the problem of a linear system of two variables given, then some students make a problem situation that is not something to do with the equation system presented by the problem, the next error is a word problem written by students not describing a problem related to the two-variable linear equation system. Not yet seen students can make a logical, complete, and correct word problem that is following the problem system of equations given. It is seen that in making a problem situation in daily life that is by the given equation system, students are less able or have difficulty to make a word problem related to the given equation system. These results are following the results of research by Ozyildirim, et al. [25], that students still experience difficulties in the process of translation, one of which is from verbal to algebra and algebra to verbal. According to Stacey and MacGregor [53], students have problems in explaining representations in words. Sert [49] stated that students feel difficulties in verbal representation.

Based on the results of students' answers it appears that in making a word problem in daily life, students fail in making connections between representations. All students represent a system of equations given in verbal form by making questions related to determining the price of an item. So in student thinking, when students are asked to make a word problem related to TVLES, then the thing most students remember is how to determine the price of an item. Yet in creating a problem situation in daily life, it is not only in the form of the price of an item. Students also do not seem to be able to understand the relationship between the completion of the system of equations obtained and relate it to create problem situations in daily life. This is consistent with the opinion of Ainsworth [9] which states that some researchers show that most students fail to understand the importance of connections between different types of representations, and also in line with the opinion of Bossé, et al. [50] stating that students rarely can translate from symbolic to verbal form.

Based on the results of interviews conducted with several students, it appears that students are indeed not accustomed to being given such questions. Usually, students are presented with problems in the form of a word problem, then students are asked to solve these problems. Therefore, in translating from symbolic representation to verbal representation, students still experience difficulties. Students were not able to maintain the appropriateness of meaning between symbolic representation and verbal representation. This is possible because students are not accustomed to using various representations in their learning so far. This is consistent with the opinion of Bossé, et al. [22] that one of the factors that influence students in translating is teacher expectations and learning experiences. Furthermore, Gagatsis and Shiakalli [24] state that middle school students are rarely asked to produce algebraic expressions based on graphs or to write appropriate verbal expressions of algebraic expressions and vice versa.

\subsection{Sudents' errors in translating from symbolic to graphical representations}

In the third problem, students are asked to translate from symbolic form to graphical representation. The equation system presented is the same as the first and second questions. Several types of errors made by students in translating from symbolic representations to graphical representations are presented in Figure 6. 


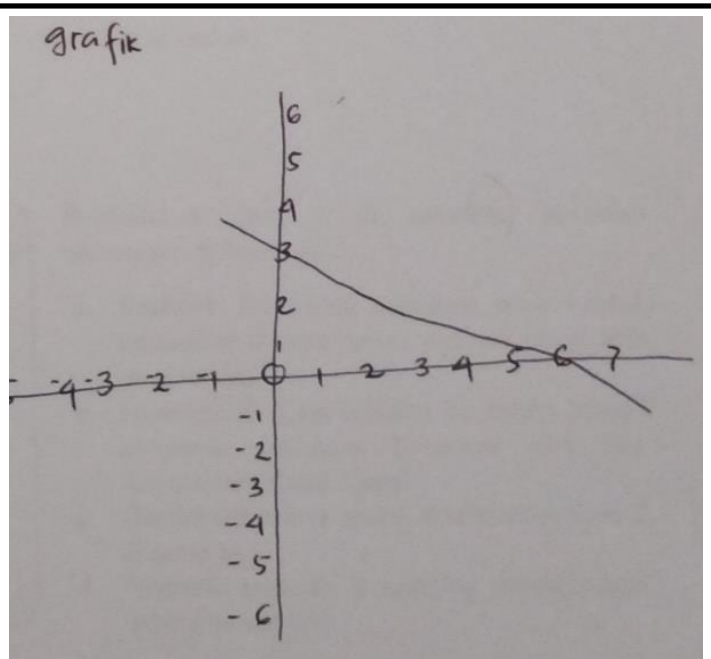

Graph representation generated by students
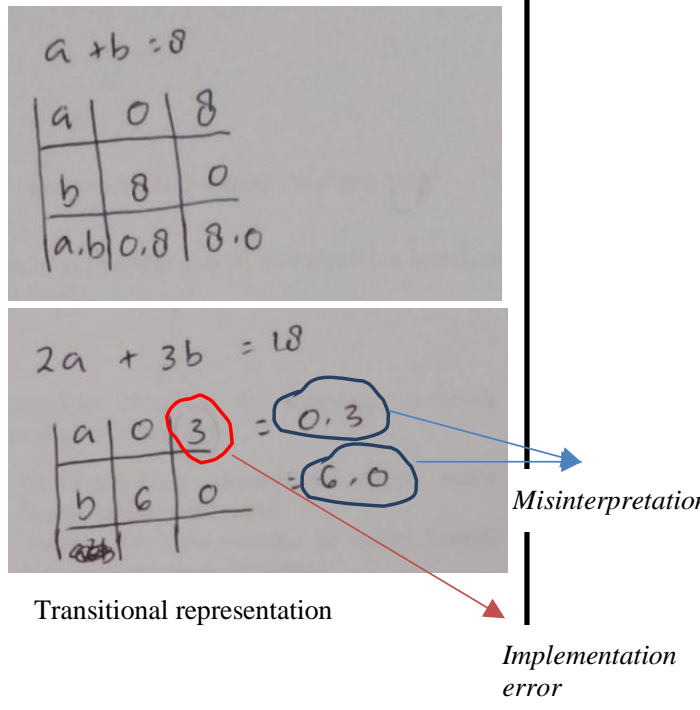

Figure 6. Examples of student answer errors in making graph representations (S68)

Based on Figure 6, it can be seen that in making a graph of the given equation system, students make transitional representations in the form of numerical representations. When viewed from the resulting transitional representation it appears that students are wrong in determining the value of $a$, when $b=0$, so the error is called an implementation error. According to Adu-Gyamfi, et al. [21], it is stated that students had implementation errors when they make computational errors. Furthermore, if further attention is paid, students also make interpretation errors, namely, students are wrong in writing sequential pairs which are the intersection points of the axis a and b, so students also experience errors in drawing graphs, this error is called misinterpretation. So, the first types of errors that students make are errors of implementation and misinterpretation. Another example of student error in translating a system of two-variable linear equations to a graph is presented in Figure 7.

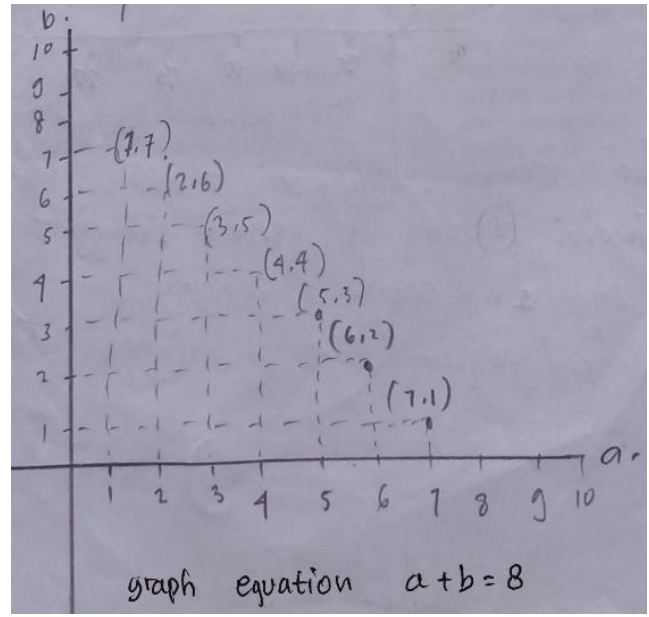

(a) Answer S32

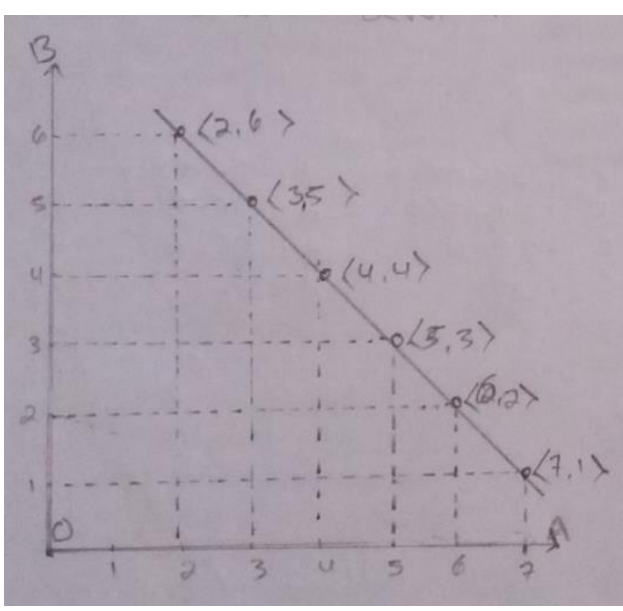

(b) Answer S24

Figure 7. Misinterpretation of drawing graphs TVLES

In Figure 7, it can be seen that in drawing a graph of a system of linear equations the two variables are presented, students only describe the graph in the form of one equation. Students have not been able to completely describe the graph of the given equation system, so the error made by students is a misinterpretation. There should be two equations illustrated, but students only draw a graph for one equation, namely $a+b=8$. So, the translations produced by students are not semantically congruent. Based on this it 
appears that students make misinterpretations. Students do not really understand how to draw a graph of a two-variable linear equation system. In the figure, it can be seen that students do not need transitional representation in drawing graphs. Another example of student error in drawing graphs is as follows.

Figure 8 shows that, when drawing a graph of a two-variable linear equation system, students only draw points which are the intersection points of the equation system. This shows that students do not really understand how to draw graphics, so students only describe the completion of the equation system. The error is called misinterpretation, so the answers written by students are not congruent semantically. The next mistakes made by students are presented in Figure 9.

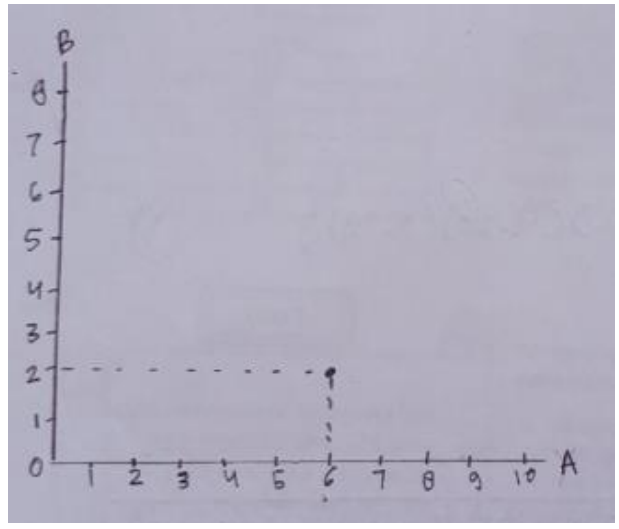

Figure 8. Another example of misinterpretation of drawing graphs (S12)

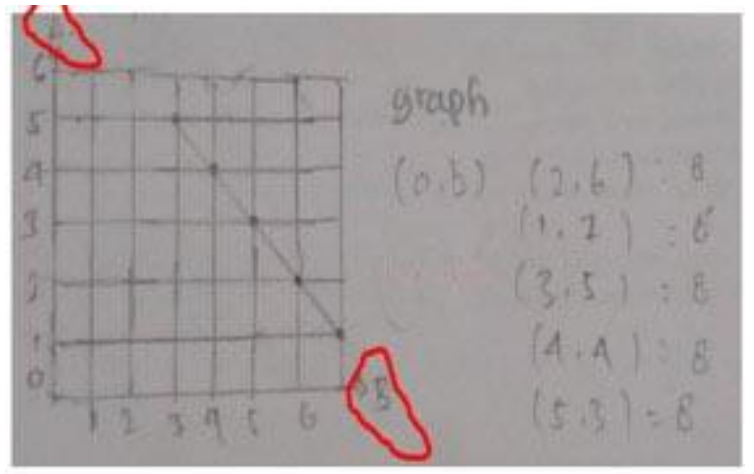

(a) Answer S45

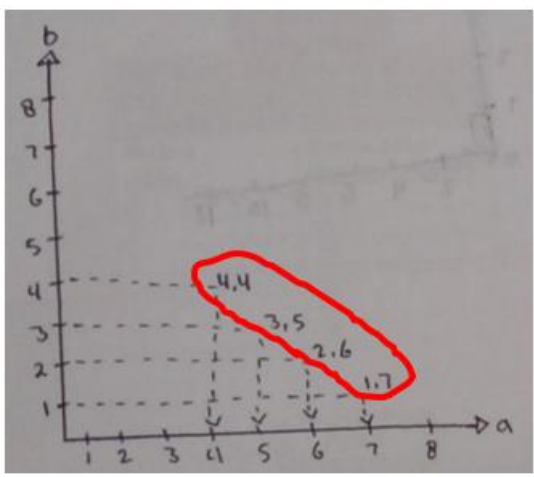

(b) Answer S1

Figure 9. Examples of misinterpretation of drawing graph

Based on the students' answers in Figure 9a, it appears that the student is reversed in making the name of the axis, so that the student makes an interpretation error. In Figure 9b, students also make an interpretation error, which should be the coordinate point written $(7,1)$ not $(1,7)$, as well as for other coordinate points. Based on the analysis of students' answers in translating from symbolic representations to graphical representations, it appears that students are still experiencing obstacles to translate the equation system into graphical form. Many students who draw the graph are not complete and some students do not understand well about how to make a graph, for example, some graphs are incomplete or the naming of the axis is sometimes reversed. This is consistent with the opinion of Hattikudur, et al. [43] which stated that students find it difficult to construct images because they have a misunderstanding about graphics, this deficiency may arise with a lack of knowledge of concepts from one representation to another. Likewise, McCoy [54] notes that students fail to make symbolically equivalent representations correctly in relationships presented in tabular or graphical formats. In addition, Dunham, et al. [55] and Kieran [56] found the inability of students to maintain semantic congruence between source and target representations involving translations from and to tables, verbal descriptions, and graphical representations, this being a frequent occurrence among students. Research results from Gürbüz and Şahin [46] found that the most difficult translation for students 
was to translate verbal representations, tables, and equations into graphs. However, it is a bit different from the results of the research by Bossé, et al. [50] stated that generally, students can translate from symbolic to graphic forms.

In translating from symbolic form to verbal form and graphic form, it can be seen that students still have difficulty in translating a certain representation, so that the ability of students in translating from one representation to various other forms of representation is not so good. As revealed by Minarni, et al. [57] that students' understanding and representation ability is still low. Ainsworth [9] stated that there is sufficient evidence that students find it difficult to translate between representations. So that this is expected to be of concern for teachers to pay attention to the translational abilities of students, especially in translating from symbolic representations to verbal and graphic representations of the same concept. In addition, teachers need to pay attention and make sure that the students comprehend the concept so that the students can translate one representation to other presentations when they are asked to do. In other words, when the concept is perfectly understandable, the students will be easy to translate it to various representations. The effect does not stop here, this skills also help the students to solve related problem.

Based on this, the teacher must realize the importance of developing the translation skills of students in mathematics learning, because the ability of students to translate between representations has to do with how the learning process is carried out by the teacher. To develop the translation skills of the students, the teacher must introduce the use of multiple representations in their learning. When the teacher teaches in many ways or many representations, students will get knowledge of various representations in their thinking [58], so that it will facilitate students to translate between representations. Ketterlin-Geller, et al. [59] stated in their research that using multiple representations helped students to improve students' translational skills in algebra. Ainsworth, et al. [26] stated that one of the tasks for learning with multiple representations is that students succeed in translating between representations. Therefore, learning needs to be given involving various representations. NCTM [2] argues that one of the most effective things in secondary school mathematics teaching is to use multiple representations and to guide students in translating between representations.

The findings in this study are expected to be a consideration for teachers in developing learning that can improve students' ability to translate between representations, in accordance with the results of this study which are related to translating from symbolic representations of verbal and graphic representations. Furthermore, the authors hope that the curriculum can develop and assist students in gaining skills and knowledge about representation translation in the future. Moreover, well-established planning and coordination of teacher education and mathematics courses for teachers at the tertiary level are the next important steps that need to be taken to discuss representation translation comprehensively. As revealed by Morris [60] that the skills to analyze student learning, including analysis of the use of student representations, must be taught explicitly to the teacher.

\section{CONCLUSION}

In translating from symbolic representations to verbal representations, there are some errors made by students, namely problem situations made by students illogically, problem situations made by students are logical but not following the system of equations presented, problem situations made by students are not there is relation to the equation system presented, and the last is the problem situation presented does not describe the concept of the given equation system. Based on this, students have not been able to maintain semantic congruence between symbolic and verbal representations. Likewise, in translating into graphical form, errors are made by students of implementation errors and interpretation errors. Students also have not been able to completely maintain the suitability of meaning in describing the graphs of the given system of equations. Besides, students' lack of understanding of concepts involving various representations also becomes a constraint factor in translating representations, because students are not accustomed to being introduced to the use of various representations in mathematics learning. Therefore, effort is needed, so that students can develop translational skills in classroom learning practice both when understanding concepts and solving problems.

\section{ACKNOWLEDGEMENTS}

This work was supported by the Beasiswa Unggulan Dosen Indonesia-Dalam Negeri (BUDI-DN) in collaboration with Lembaga Pengelola Dana Pendidikan (LPDP). 


\section{REFERENCES}

[1] B. L. Chang, J. G. Cromley, and N. Tran, "Coordinating Multiple Representations in a Reform Calculus Textbook," Int. J. Sci. Math. Educ., vol. 14, no. 8, pp. 1475-1497, 2016.

[2] NCTM, Principle and Standards for School Mathematics. Reston, Va, 2000.

[3] J. Olive and G. Caglayan, "Learners' Difficulties with Quantitative Units In Algebraic Word Problem and The Teacher's Interpretation of Those Difficulties," Int. J. Sci. Math. Educ., vol. 6, no. 2, pp. 269-292, 2008.

[4] D. A. Stylianou, "Teachers' conceptions of representation in middle school mathematics," Journal of Mathematics Education, vol. 13, no. 4, pp. 325-343, 2010.

[5] L. Zhe, "Survey of Primary Students ' Mathematical Representation Status and Study on the Teaching Model of Mathematical Representation," Journal of Mathematics Education, vol. 5, no. 1, pp. 63-76, 2012.

[6] M. Brown, M. J. Bossé, and K. Chandler, "Student errors in dynamic mathematical environments," Int. J. Math. Teach. Learn., vol. 17, no. 1, pp. 1-27, 2016.

[7] I. S. Putra, M. Masriyah, and R. Sulaiman, "Students' Translation Ability of Mathematical Representations (Symbolic and Visual) Based on Their Learning Styles," J. Phys. Conf. Ser., vol. 1108, no. 1, 2018.

[8] F. Ulusoy and Z. Argun, "Secondary school students' representations for solving geometric word problems in different clinical interviews," International Journal of Education in Mathematics, Science and Technology, vol. 7, no. 1, pp. 73-92, 2019.

[9] S. E. Ainswroth, "Designing Effective multi-representational Learning Environments," PhD Thesis and technical report number 47, ESRC Cent. Res. Dev. Instr. Train. Univ. Nottingham, 1999.

[10] C. Blake and E. Scanlon, "Reconsidering simulations in science education at a distance: Features of effective use," Journal of Computer Assisted Learning., vol. 23, no. 6, pp. 491-502, 2007.

[11] W. Y. Hwang, N. S. Chen, J. J. Dung, and Y. L. Yang, "Multiple Representation Skills and Creativity Effects on Mathematical Problem Solving using a Multimedia Whiteboard System," Journal of Educational Technology \& Society, vol. 10, no. 2, pp. 191-212, 2007.

[12] S. Inayah, "Improved problem solving skills and mathematical multiple representations using a quantum learning model (in Bahasa)," KALAMATIKA J. Pendidik. Mat., vol. 3, no. 1, pp. 1-16, 2018.

[13] R. Lesh, T. Post, and M. Behr, "Representations and Translations among Representations in Mathematics Learning and Problem Solving," 1987. [Online]. Available: http://www.cehd.umn.edu/ci/rationalnumberproject/87_5.html.

[14] Y. H. Lin, M. Wilson, and C. L. Cheng, "An investigation of the nature of the influences of item stem and option representation on student responses to a mathematics test," European Journal of Psychology of Education, vol. 28, no. 4, pp. 1141-1161, 2013.

[15] D. A. Stylianou, "An examination of middle school student' representation practices in mathematical problem solving through the lens of expert work: Towards an organizing scheme," Educational Studies in Mathematics, vol. 76, pp. 265-280, 2011.

[16] D. J. Within and P. Whitin, "Making Sense of Fractions and Percentages," Teach. Child. Math., vol. 18, no. 8, pp. 490-496, 2012.

[17] Nizaruddin, Muhtarom, and Y. H. Murtianto, "Exploring of Multi Mathematical Representation Capability in Problem Solving on Senior High School Students," Probl. Educ. 21 Century, vol. 75, no. 6, pp. 591-598, 2017.

[18] R. Kang and D. Liu, "The Importance of Multiple Representations of Mathematical Problems: Evidence from Chinese Preservice Elementary Teachers' Analysis of a Learning Goal," Int. J. Sci. Math. Educ., vol. 16, no. 1, pp. 125-143, 2018.

[19] Z. Pehlivan and F. Aslan-tutak, "A Look into Turkish Preservice Teachers' Translation Skills : Case for Model Representations," Eleventh Congress of the European Society for Research in Mathematics Education, Utrecht University, Utrecht, Feb. 2019.

[20] S. Ainsworth, "The functions of multiple representations," Comput. Educ., vol. 33, no. 2-3, pp. 131-152, 1999.

[21] K. Adu-Gyamfi, L. V. Stiff, and M. J. Bossé, "Lost in Translation: Examining Translation Errors Associated with Mathematical Representations," Sch. Sci. Math., vol. 112, no. 3, pp. 159-170, 2012.

[22] M. J. Bossé, K. Adu-Gyamfi, and M. Cheetham, "Translations Among Mathematical Representations: Teachers Beliefs and Practices," Int. J. Math. Teach. Learn., vol. 15, no. 6, pp. 1-23, 2011.

[23] M. Bossé, K. Adu-Gyamfi, and K. Chandler, "Students' Differentiated Translation Processes," Int. J. Math. Teach. Learn., no. 828, Mar. 2014.

[24] A. Gagatsis and M. Shiakalli, "Ability to translate from one representation of the concept of function to another and mathematical problem solving," Educ. Psychol., vol. 24, no. 5, pp. 645-657, 2004.

[25] F. Ozyildirim, S. Ipek, and O. Akkus, "Seventh Grade Student's Translational Skills among Mathematical Representations," Int. J. Learn., vol. 16, no. 3, pp. 197-206, 2009.

[26] S. Ainsworth, P. Bibby, and D. Wood, "What We Learn When We Engage in Design," J. Learn. Sci., vol. 11, no. 1, pp. 25-61, 2002.

[27] F. Kara and L. Incikabi, "Sixth grade students' skills of using multiple representations in addition and subtraction operations in fractions," Int. Electron. J. Elem. Educ., vol. 10, no. 4, pp. 463-474, 2018.

[28] R. M. Panasuk, "Taxonomy for assessing conceptual understanding in Algebra using multiple representations," College Student Journal, vol. 45, no. 2, pp. 219-232, 2011.

[29] R. M. Panasuk and M. L. Beyranevand, "Algebra Students' Ability to Recognize Multiple Representations and Achievement," Int. J. Math. Teach. Learn., 2010.

[30] D. Rahmawati, P. Purwanto, S. Subanji, E. Hidayanto, and R. B. Anwar, "Process of mathematical representation translation from verbal into graphic," Int. Electron. J. Math. Educ., vol. 12, no. 4, pp. 367-381, 2017. 
[31] K. Adu-Gyamfi, M. J. Bossé, and K. Lynch-Davis, "Three types of mathematical representational translations: Comparing empirical and theoretical results," School Science and Mathematics, vol. 119, no. 7. pp. 396-404, 2019.

[32] D. D. Z. Helingo, S. M. Amin, and M. Masriyah, "Translation process of mathematics representation: From graphics to symbols and vice versa," J. Phys. Conf. Ser., vol. 1188, no. 1, 2019.

[33] M. Molina, S. Rodríguez-Domingo, M. C. Cañadas, and E. Castro, "Secondary School Students' Errors in the Translation of Algebraic Statements," Int. J. Sci. Math. Educ., vol. 15, no. 6, pp. 1137-1156, 2017.

[34] C. Janvier, "Translation process in mathematics education," in C. Janvier, Ed. Problems of representation in mathematics learning and problem solving. Hillsdale, NJ: Lawrence Erlbaum Associates, 1987, pp. 27-31.

[35] E. Lesh, et al., "Conceptual models in applied mathematical problem solving," in R. Lesh M. Landau, Eds. Acquisitionof Mathematics Concepts and Processes. New York: Academic Press, 1983, pp. 263-343.

[36] C. Sa'dijah, et al., "Teachers' Representation in Solving Mathematical Word Problem," Proceedings of 2018 2nd International Conference on Education and Multimedia Technology (ICEMT 2018), 2018, pp. 85-89.

[37] R. S. Baker, A. T. Corbett, and K. R. Koedinger, "Toward a model of learning data representations," Proc. 23rd Annu. Conf. Cogn. Sci. Soc., pp. 45-50, 2001.

[38] K. Bossé, Michael and Chandler, "Situating Student Errors: Linguistic-to-Algebra Translation Errors," Igarss 2014, no. 1, pp. 1-5, 2014.

[39] J. Clement, "Algebra Word Problem Solutions: Thought Underlying Processes a Common Misconception," J. Res. Math. Educ., vol. 13, no. 1, pp. 16-30, 1982.

[40] J. Clement, J. Lochhead, and G. S. Monk, "Translation Difficulties in Learning Mathematics," Am. Math. Mon., vol. 88 , no. 4 , pp. $286-290,1981$

[41] A. Duru and O. Koklu, "Middle school students' reading comprehension of mathematical texts and algebraic equations," Int. J. Math. Educ. Sci. Technol., vol. 42, no. 4, pp. 447-468, 2011.

[42] A. Gagatsis, C. Christou, and I. Elia, "The Nature of Multiple Representations in Developing Mathematical Relationships 1," G.R.I.M, vol. 14, no. 2002, pp. 150-159, 2004

[43] S. Hattikudur, et al., "Constructing Graphical Representations: Middle Schoolers' Intuitions and Developing Knowledge About Slope and Y-intercept,"Sch. Sci. Math., vol. 112, no. 4, pp. 230-240, 2012.

[44] Z. R. Mevarech and B. Kramarsky, "From Verbal Descriptions to Graphic Representations: Staility and Change in Students' Alternative Conception," Educational Studies in Mathematics, vol. 32, no. 3, pp. 229-263, 1997.

[45] F. S. Ng and K. Lee, "The Model Method: Singapore Children's Tool for Representing and Solving Algebraic Word Problems," J. Res. Math. Educ., vol. 40, no. 3, pp. 282-313, 2009.

[46] R. Gürbüz and S. Şahin, "Grade Students ' Skills In Translating Among Multiple Representations," Kastamonu Education Journal, vol. 23, no. 4, pp. 1863-1884, 2015.

[47] M. Molina, S. Rodríguez-Domingo, M. C. Cañadas, and E. Castro, "Secondary School Students' Errors in the Translation of Algebraic Statements,” Int. J. Sci. Math. Educ., vol. 15, no. 6, pp. 1137-1156, 2017.

[48] R. Johar and K. R. Lubis, "The analysis of students' mathematical representation errors in solving word problem related to graph," J. Ris. Pendidik. Mat., vol. 5, no. 1, p. 96, 2018.

[49] O. Sert, "Eighth Grade Students' Skills in Translating among Different Representations of Algebraic Concepts," Unpublished Master Thesis, Middle East Technical University, Ankara, 2007.

[50] M. J. Bossé, K. Adu-Gyamfi, and M. R. Cheetham, "Assessing the difficulty of mathematical translations: Synthesizing the literature and novel findings," Int. Electron. J. Math. Educ., vol. 6, no. 3, pp. 113-133, 2011.

[51] A. Veloo, H. N. Krishnasamy, and W. S. Wan Abdullah, "Types of student errors in mathematical symbols, graphs and problem-solving," Asian Soc. Sci., vol. 11, no. 15, pp. 324-334, 2015.

[52] M. J. Padilla, D. L. McKenzie, and E. L. Shaw, "An Examination of the Line Graphing Ability of Students in Grades Seven Through Twelve," Sch. Sci. Math., vol. 86, no. 1, pp. 20-26, 1986.

[53] K. Stacey and M. Macgregor, "Building Foundation for Algebra," Math. Teach. Middle Sch., vol. 2, no. 4, pp. 252-260, 1997.

[54] L. P. McCoy, "Multitasking algebra representation," Proceedings of the Sixteenth Annual Conference for the Psychology of Mathematics Education, 1994, pp. 173-179.

[55] P. H. Dunham, A. Osborne, P. H. Dunham, and A. Osborne, "Learning How to See: Students Graphing Difficulties," Focus Learn. Probl. Math., vol. 13, no. 4, pp. 35-9, 1991.

[56] C. Kieran, "Function, graphing, and technology: Integrating research on learning and instruction," T. A. Romberg, E. Fennema \& T. P. Carpenter, Eds. Integrating research on the graphical representation of functions. Hillsdale, NJ: Lawrence Erlbaum Associates, 1993, pp. 189-238.

[57] A. Minarni, E. E. Napitupulu, and R. Husein, "Mathematical Understanding and Representation Ability of Public Junior High School in North Sumatra," Jme, vol. 7, no. 1, pp. 43-56, 2016.

[58] N. Nurrahmawati, C. Sa'dijah, S. Sudirman, and M. Muksa, "Multiple representations' ability in solving word problem," Int. J. Recent Technol. Eng., vol. 8, no. 1C2, pp. 737-745, 2019.

[59] L. R. Ketterlin-Geller, K. Jungjohann, D. J. Chard, and S. Baker, "From arithmetic to algebra," Educ. Leadersh., vol. 65 , no. 3 , pp. 66-71, 2007.

[60] A. K. Morris, “Assessing Pre-Service Teachers' Skills for Analyzing Teaching," J. Math. Teach. Educ., vol. 9, no. 5, pp. 471-505, 2006 